\title{
Picrasma quassiodes (D. Don) Benn. attenuates lipopolysaccharide (LPS)-induced acute lung injury
}

\author{
JAE-WON LEE ${ }^{1}$, JI-WON PARK ${ }^{1}$, NA-RAE SHIN ${ }^{1,2}$, SO-YEON PARK $^{1}$, OK-KYOUNG KWON ${ }^{1,3}$, \\ HYUN AH PARK ${ }^{1,4}$, YOURIM LIM ${ }^{1,5}$, HYUNG WON RYU ${ }^{1}$, HEUNG JOO YUK ${ }^{1}$, \\ JUNG HEE KIM $^{1}$, SEI-RYANG OH ${ }^{1}$ and KYUNG-SEOP AHN ${ }^{1}$
}

\begin{abstract}
${ }^{1}$ Natural Medicine Research Center, Korea Research Institute of Bioscience and Biotechnology, Chungju-si, Chungbuk 363-883; ${ }^{2}$ College of Veterinary Medicine, Chonnam National University, Gwangju, Gyeonggi 500-757; ${ }^{3}$ Department of Toxicology, College of Pharmacy, Chungnam National University; ${ }^{4}$ College of Pharmacy, Chungnam National University, Daejeon 305-764;

${ }^{5}$ College of Pharmacy, Chungbuk National University, Cheongju-si, Chungbuk 361-763, Republic of Korea
\end{abstract}

Received November 3, 2015; Accepted June 15, 2016

DOI: $10.3892 / \mathrm{ijmm} .2016 .2669$

\begin{abstract}
Picrasma quassiodes (D.Don) Benn. (PQ) is a medicinal herb belonging to the family Simaroubaceae and is used as a traditional herbal remedy for various diseases. In this study, we evaluated the effects of PQ on airway inflammation using a mouse model of lipopolysaccharide (LPS)-induced acute lung injury (ALI) and LPS-stimulated RAW 264.7 cells. ALI was induced in C57BL/6 mice by the intranasal administration of LPS, and PQ was administered orally 3 days prior to exposure to LPS. Treatment with PQ significantly attenuated the infiltration of inflammatory cells in the bronchoalveolar lavage fluid (BALF). PQ also decreased the production of reactive oxygen species (ROS) and pro-inflammatory cytokines, such as tumor necrosis factor (TNF)- $\alpha$ and interleukin (IL)-6 in BALF. In addition, PQ inhibited airway inflammation by reducing the expression of inducible nitric oxide synthase (iNOS) and by increasing the expression of heme oxygenase-1 (HO-1) in the lungs. Furthermore, we demonstrated that PQ blocked the activation of mitogen-activated protein kinase (MAPK) and nuclear factor- $\kappa \mathrm{B}(\mathrm{NF}-\kappa \mathrm{B})$ in the lungs of mice with LPS-induced ALI. In the LPS-stimulated RAW 264.7 cells,
\end{abstract}

Correspondence to: Dr Kyung-Seop Ahn, Natural Medicine Research Center, Korea Research Institute of Bioscience and Biotechnology, 30 Yeongudanji-ro, Cheongwon-gun, Chungju-si, Chungbuk 363-883, Republic of Korea

E-mail: ksahn@kribb.re.kr

Abbreviations: ALI, acute lung injury; BALF, bronchoalveolar lavage fluid; HO-1, heme oxygenase-1; IL-6, interleukin-6; iNOS, inducible nitric oxide synthase; LPS, lipopolysaccharide; MAPK, mitogenactivated protein kinase; MCP-1, monocyte chemoattractant protein-1; $\mathrm{NF}-\kappa \mathrm{B}$, nuclear factor- $\mathrm{B}$; PQ, Picrasma quassiodes (D. Don) Benn.; ROS, reactive oxygen species; TNF- $\alpha$, tumor necrosis factor- $\alpha$

Key words: acute lung injury, Picrasma quassiodes (D. Don) Benn., neutrophils, inducible nitric oxide synthase, heme oxygenase-1, nuclear factor- $\kappa \mathrm{B}$, mitogen-activated protein kinase
PQ inhibited the release of pro-inflammatory cytokines and increased the mRNA expression of monocyte chemoattractant protein-1 (MCP-1). Treatment with PQ decreased the translocation of nuclear factor $(\mathrm{NF})-\kappa \mathrm{B}$ to the nucleus, and increased the nuclear translocation of nuclear factor erythroid-2-related factor 2 (Nrf2) and the expression of HO-1. PQ also inhibited the activation of $\mathrm{p} 38$ in the LPS-stimulated RAW 264.7 cells. Taken together, our findings demonstrate that PQ exerts antiinflammatory effects against LPS-induced ALI, and that these effects are associated with the modulation of iNOS, HO-1, $\mathrm{NF}-\kappa \mathrm{B}$ and MAPK signaling. Therefore, we suggest that PQ has therapeutic potential for use in the treatment of ALI.

\section{Introduction}

Acute lung injury (ALI) is a critical illness which plays a pivotal role in the death of patients in the intensive care unit $(1,2)$. ALI is characterized by an uncontrolled inflammatory response in the lungs, resulting in airway dysfunction (3). The most common cause of ALI is an exposure to the structural component of a Gramnegative bacterial membrane, lipopolysaccharide (LPS) (4). In response to bacterial LPS stimulation, neutrophils migrate across the endothelium and epithelium into the alveolar space, and are subsequently activated, causing the excessive production of proinflammatory molecules, such as reactive oxygen species (ROS) and pro-inflammatory cytokines (5). The neutrophil-derived overproduction of ROS has been shown to cause lung tissue damage in animal models of LPS-induced ALI $(6,7)$. Inducible nitric oxide synthase (iNOS) in neutrophils and alveolar macrophages (AM) plays a crucial role in the development of ALI by modulating pulmonary neutrophil infiltration $(8,9)$. AM regulate neutrophil recruitment in endotoxin-induced lung injury by controlling monocyte chemoattractant protein-1 (MCP-1) (10). Tumor necrosis factor- $\alpha$ (TNF)- $\alpha$ and interleukin-6 (IL-6) secreted by AM are early response cytokines which stimulate neutrophils, and these activated neutrophils release proteases and oxidants (11). TNF- $\alpha$ and IL- 6 also stimulate other cells locally, such as macrophages, epithelial cells and endothelial cells to discharge other pro-inflammatory chemokines involved 
in the pathogenesis of ALI $(12,13)$. The influx and activation of neutrophils within the lungs is a hallmark of ALI, and macrophages are key effector cells that are involved in the process of ALI $(11,14)$.

Nuclear factor- $\kappa \mathrm{B}(\mathrm{NF}-\kappa \mathrm{B})$ and mitogen-activated protein kinases (MAPKs) are involved in regulating pro-inflammatory mediators and cytokines in LPS-induced ALI $(15,16)$. The activation of the NF- $\mathrm{NB}$ and MAPK pathways in lung tissues is one of the major characteristics of ALI (17). The inhibition of the activation of the NF- $\kappa \mathrm{B}$ and MAPKs pathways is believed to alleviate ALI by blocking the induction of inflammatory mediators, such as iNOS, TNF- $\alpha$, IL-6 and MCP-1 $(13,17)$.

The expression of heme oxygenase-1 (HO-1), an antioxidant defense protein, can be induced by stimulants such as oxidants and inflammatory cytokines $(18,19)$. There is recent evidence to indicate that the upregulation of HO-1 is involved in the resolution of inflammation, and attenuates LPS-induced ALI through the suppression of neutrophil infiltration (20). It has also been reported that the upregulation of HO-1 attenuates severe lung injury through the suppression of the migration of macrophages, increasing the survival of animals (21).

Picrasma quassioides (D. Don) Benn. (PQ) is widely distributed in most areas of mainland China, and the branches of this plant are used as a traditional folk medicine for the treatment of a variety of diseases, such as hypertension (22), colitis (23), gastroenteritis and cancer (24). The major active compounds in PQ are $\beta$-carbolines and canthin-6-one alkaloids (24) which have been reported to possess various activities, such as anti-inflammatory and anti-hypertensive activities $(22,23)$. 4-Methoxy-5-hydroxycanthin-6-one is one of the major active constituents of $\beta$-carbolines and cathinone alkaloids isolated from PQ. It has been shown to inhibit the production of inflammatory mediators, such as iNOS and TNF- $\alpha$ in LPS-stimulated RAW 264.7 macrophages, and to reduce the development of carrageenan-induced paw edema and adjuvant-induced chronic arthritis in rats (25). In our previous study, we demonstrated that PQ inhibited airway inflammation in a murine model of allergic asthma (26). However, to the best of our knowledge, the anti-inflammatory effects of PQ have not yet been demonstrated in a model of LPS-induced ALI. Therefore, in this study, we evaluated the effects of PQ in a mouse model of LPS-induced ALI and in LPS-stimulated RAW 264.7 macrophages.

\section{Materials and methods}

Preparation of $P Q$ extract. PQ was collected from Baegunsan Mountain of Gwangyang-si, Jeollanam-do, Korea. A voucher specimen recorded as KRIB 0001101 has been deposited at the herbarium of the Korea Research Institute of Bioscence and Biotechnolgy (KRIBB). After drying and grinding the bark of the stem of PQ, the powder $(50 \mathrm{~g})$ was added to 100 liters of methanol. The extraction was performed using the method of repercolation at room temperature. The extract was filtered and concentrated using a rotary evaporator (N-1200AV-W; T.R.K.EYELA, Tokyo, Japan) under reduced pressure, thereby obtaing $2.07 \mathrm{~g}$ of PQ methanolic extract. In the following experiment, PQ was dissolved in dimethyl sulfoxide (DMSO) at a concentration of $20 \mathrm{mg} / \mathrm{ml}$, and then diluted to various concentrations prior to use.
Animal model of LPS-induced ALI. Specific pathogen-free male C57BL/6N mice (6 weeks old) were obtained from Koatech Co. (Pyeongtaek, Korea) and used after 2 weeks of quarantine and acclimatization. They were housed in groups of 7 under standard conditions with food and water. Briefly, the mice ( $\mathrm{n}=7 /$ group) were divided into 4 groups as follows: i) the normal control (NC) group; ii) the LPS group; iii) the dexamethasone (DEX; $3 \mathrm{mg} / \mathrm{kg}$ ) group (used as a positive control); and iv) the PQ group (administered 5 and $15 \mathrm{mg} /$ kg PQ). PQ and DEX were dissolved with $0.5 \%$ carboxymethyl cellulose (CMC), and were administered orally from day 0 to day 2 . The mice were exposed to LPS (10 $\mu \mathrm{g} / \mathrm{mouse})$ intranasally $1 \mathrm{~h}$ after the final DEX and PQ treatment, as previously described (3). All the experimental procedures were performed in accordance with the procedures approved by the Institutional Animal Care and Use Committee of the Korea Research Institute of Bioscience and Biotechnology and performed in compliance with the National Institutes of Health Guidelines for the Care and Use of Laboratory Animals and Korean National Laws for Animal Welfare.

Collection of bronchoalveolar lavage fluid (BALF), and inflammatory cell counting. To obtain the BALF, ice-cold PBS $(0.7 \mathrm{ml})$ was infused into the lungs of the mice twice and withdrawn each time using a tracheal cannula (a total volume of $1.4 \mathrm{ml}$ ). The collected BALF was centrifuged for $5 \mathrm{~min}$ at 1,500 rpm and the BALF differential cell count was determined using Diff-Quik ${ }^{\circledR}$ staining reagent according to the manufacturer's instructions, and as previously described (3).

Measurement of ROS and pro-inflammatory cytokines in $B A L F$. The intracellular levels of ROS were determined using 2',7'-dichlorofluorescein diacetate (DCFH-DA; Sigma Aldrich, St. Louis, MO, USA). Briefly, BALF cells were washed with PBS and incubated with $20 \mu \mathrm{M}$ DCFH-DA for $10 \mathrm{~min}$ at $37^{\circ} \mathrm{C}$. The activity of intracellular ROS was then detected by measuring the fluorescence at $488 \mathrm{~nm}$ excitation and $525 \mathrm{~nm}$ emission on a fluorescence plate reader (Perkin-Elmer, Waltham, MA, USA). The levels of pro-inflammatory cytokines (TNF- $\alpha$ and IL-6) in BALF were measured using ELISA kits according to the manufacturer's instructions (R\&D Systems, Minneapolis, MN, USA). Blood was collected from the inferior vena cava, and the levels of IL-6 in serum were determined using ELISA following the manufacturer's instructions (R\&D Systems). The absorbance was measured at $450 \mathrm{~nm}$ was determined using an ELISA reader (Molecular Devices, Sunnyvale, CA, USA).

Western blot analysis. The lung tissue was homogenized (1/10 w/v) using a homogenizer with tissue lysis/ extraction reagent, containing a protease inhibitor cocktail (both from Sigma-Aldrich). Equal amounts of the total cellular protein $(30 \mu \mathrm{g})$ were resolved by $12 \%$ SDS-polyacrylamide gels and transferred onto a nitrocellulose membrane. The membrane was blocked by incubation with 5\% skim milk in TBST for $1 \mathrm{~h}$, and incubated overnight at $4^{\circ} \mathrm{C}$ with the appropriate primary antibody. Specific antibodies against Nrf2 (ab137550, 1;1,000; Abcam, Cambridge, MA, USA), HO-1 (ab137749, 1;1,000; Abcam) p-p38 (1:1,000; ADI-KAP-MA022, 1:1,000; Enzo Life Sciences, Farmingdale, NY, USA), p38 (sc-7149, 1:1,000; Santa Cruz Biotechnology, Santa Cruz, CA, USA), p-ERK (\#9106, 


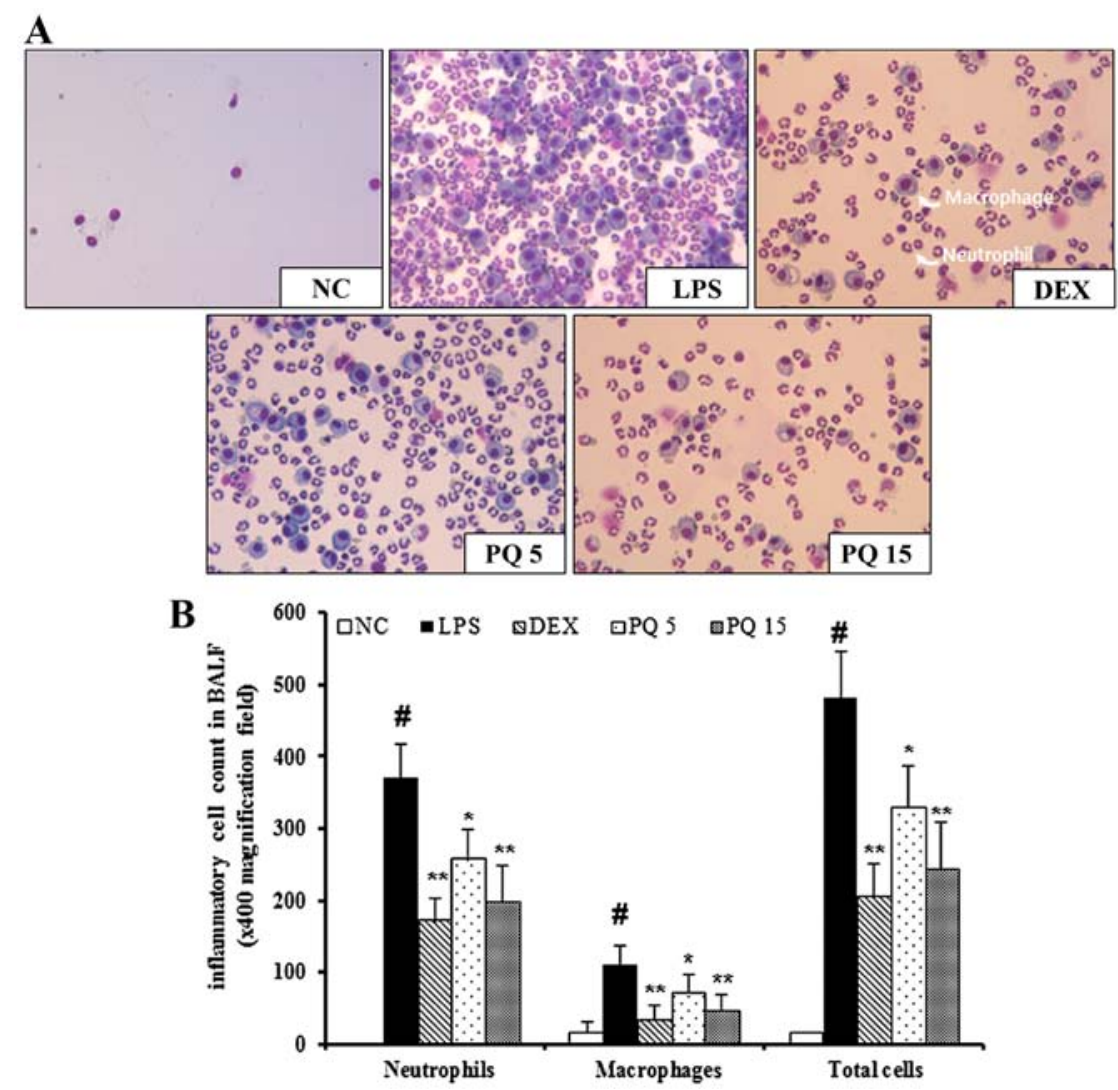

Figure 1. (A and B) Picrasma quassiodes (D. Don) Benn. (PQ) inhibits the infiltration of inflammatory cells in mouse bronchoalveolar lavage fluid (BALF) induced by lipopolysaccharide (LPS). BALF differential cell count was determined using the Diff-Quik ${ }^{\circledR}$ staining reagent according to the manufacturer's instructions (magnification, $\mathrm{x} 400$ ). The values expressed as the means $\pm \mathrm{SD}$ ( $\mathrm{n}=7$ mice per group). NC, normal control mice; LPS, mice administered LPS; DEX, mice administered dexamethasone ( $3 \mathrm{mg} / \mathrm{kg}$ ) + LPS; PQ 5 and 15, mice administered 5 or $15 \mathrm{mg} / \mathrm{kg}$ PQ + LPS. Data are expressed as the means $\pm \mathrm{SD}$; ${ }^{*} \mathrm{p}<0.01 \mathrm{indicates}$ a statistically significant difference from the normal control group; ${ }^{*} \mathrm{p}<0.05$ and ${ }^{* *} \mathrm{p}<0.01$ indicate statistically significant differences compared to the LPS group.

1:1,000; Cell Signaling Technology Inc., Danvers, MA, USA), ERK (sc-154, 1:1,000; Santa Cruz Biotechnology), p-JNK (KAP-SA011, 1:1,000; Enzo Life Sciences), JNK (sc-474, 1:1,000), IкB (sc-371, 1:1,000), p65 (sc-372, 1,000) (all from Santa Cruz Biotechnology), p-p65 (\#3033, 1:1,000; Cell Signaling Technology Inc.), iNOS (ADI-905-431, 1:1,000; Enzo Life Sciences) and $\beta$-actin (\#4967, 1:2,500; Cell Signaling Technology Inc.) were diluted in 5\% skim milk. The blots were washed with TBST and incubated with a 1:2,000 dilution of a horseradish peroxidase (HRP)-conjugated secondary antibody for $2 \mathrm{~h}$ at room temperature. The blots were washed with TBST and developed using an enhanced chemiluminescence (ECL) kit (Thermo Fisher Scientific, Inc., Rockford, IL, USA). The protein bands were visualized using a LAS-4000 luminescent image analyzer (Fujifilm, Tokyo, Japan) and quantified by densitometry (Fuji Multi Gauge software version 3.0).

Isolation of nuclear extract. RAW 264.7 murine macrophages $\left(2 \times 10^{5}\right.$ cells $/ \mathrm{ml}$; ATCC, Manassas, VA, USA) were cultured in 6-well plates, treated with PQ for $1 \mathrm{~h}$ and stimulated with $0.5 \mu \mathrm{g} /$ $\mathrm{ml}$ of LPS. The cells were harvested and washed twice with ice-cold PBS. Nuclear and cytoplasmic fractions were prepared using NE-PER nuclear and cytoplasmic extraction reagents (Pierce, Rockford, IL, USA), according to the manufacturer's instructions. The nuclear translocation of NF- $\mathrm{kB}$ and Nrf2 was determined by western blot analysis. PARP is a nuclear protein which was used as an internal control.
Reverse transcription-polymerase chain reaction (RT-PCR). The RAW 264.7 macrophages were treated with PQ in the absence or presence of LPS $(0.5 \mu \mathrm{g} / \mathrm{ml})$ for $6 \mathrm{~h}$. Total RNA was isolated using TRIzol ${ }^{\text {TM }}$ reagent (Invitrogen Life Technologies, Carlsbad, CA, USA) according to the instructions provided by the manufacturer, and the reverse transcription reaction was performed using a kit producing cDNA (Qiagen, Hilden, Germany). Polymerase chain reactions were performed using specific forward and reverse primers as follows: MCP-1 forward, 5'-AGGTCCCTGTCATGCTTCTG-3' and reserve, 5'-TCT GGACCCATTCCTTCTTG-3'; HO-1 forward, 5'-TGAAGGA GGCCACCAAGGAGG-3' and reverse, 5'-AGAGGTCACC CAGGTAGCGGG-3'; and $\beta$-actin forward, 5'-TGTTTG AGACCTTCAACACC-3' and reserve, 5'-CGCTCATTGCCG ATAGTGAT-3'. Parallel PCR analysis was run for the housekeeping gene, $\beta$-actin, to normalize the data for differences in mRNA quantity and integrity. The PCR products were fractionated by $1.5 \%$ agarose gel electrophoresis and stained with $5 \mu \mathrm{g} / \mathrm{ml}$ ethidium bromide. These experiments were performed in triplicate.

Histological analysis. Lung tissues were obtained to evaluate the effects of PQ at $24 \mathrm{~h}$ after LPS injection. Mice were anesthetized by an intraperitoneal injection of pentobarbital (50 mg/kg; Hanlim Pharm. Co., Seoul, Korea). The lung tissues were washed and fixed in $4 \%(\mathrm{v} / \mathrm{v})$ paraformaldehyde. The lung tissues were embedded in paraffin, sectioned at $4 \mu \mathrm{m}$ 

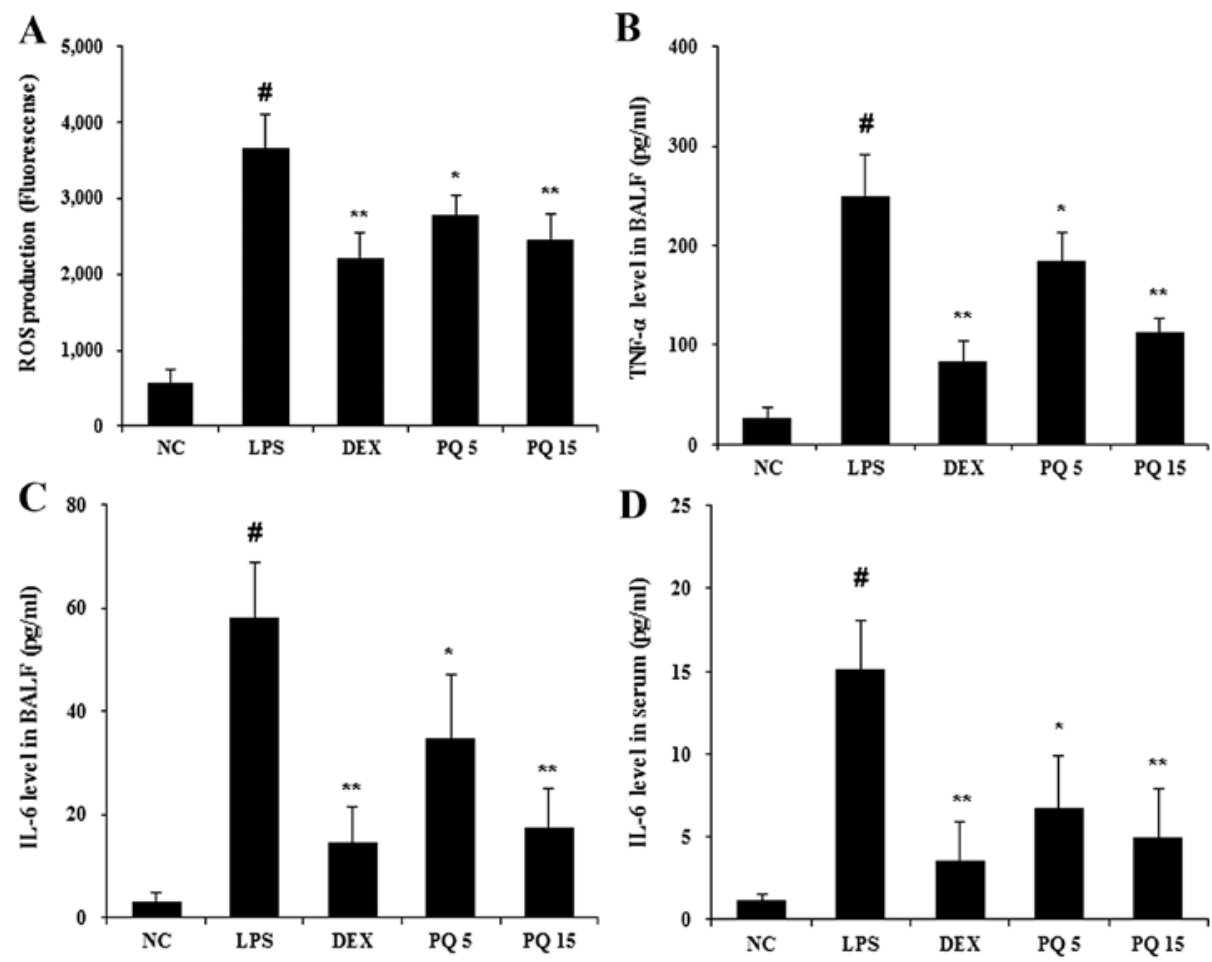

Figure 2. Picrasma quassiodes (D. Don) Benn. (PQ) reduces the levels of reactive oxygen species (ROS) and pro-inflammatory cytokines, such as tumor necrosis factor- $\alpha$ (TNF)- $\alpha$ and interleukin-6 (IL-6) in bronchoalveolar lavage fluid (BALF) and attenuates the release of IL-6 in serum induced by lipopolysaccharide (LPS). The levels of (A) ROS, (B) TNF- $\alpha$ and (C and D) IL-6 were measured by ELISA. The absorbance was measured at $450 \mathrm{~nm}$ using a microplate reader. NC, normal control mice; LPS, mice administered LPS; DEX, mice administered dexamethasone $(3 \mathrm{mg} / \mathrm{kg})+\mathrm{LPS}$; PQ 5 and 15 , mice administered 5 or $15 \mathrm{mg} / \mathrm{kg}$ PQ + LPS. Data are expressed as the means $\pm \mathrm{SD} ;{ }^{*} \mathrm{p}<0.01$ indicates a statistically significant difference from the normal control group; ${ }^{*} \mathrm{p}<0.05$ and ${ }^{* *} \mathrm{p}<0.01$ indicate statistically significant differences compared to the LPS group.

thickness, and stained with an H\&E solution (Sigma-Aldrich) to estimate inflammation in peribronchial and alveolar lesions. Quantitative analysis of inflammation was performed using an image analyzer (Molecular Devices).

Cell viability. The viability of the RAW 264.7 macrophages was examined following the treatment of the cells with various concentrations $(0,2.5,5,10$ and $20 \mu \mathrm{g} / \mathrm{ml})$ of PQ and LPS $(0.5 \mu \mathrm{g} / \mathrm{ml})$. Cell viability was examined by 3-(4,5-dimethylthiazol-2-yl)-2,5-diphenyltetrazolium bromide (MTT) assay. The cells were seeded at $1 \times 10^{4}$ cells per well of a96-well plate and incubated with $\mathrm{PQ}$ at various concentrations for $24 \mathrm{~h}$ at $37^{\circ} \mathrm{C}$. After incubation, MTT $(0.5 \mathrm{mg} / \mathrm{ml}$ in PBS) was added to each well, and the cells were incubated for $2 \mathrm{~h}$ at $37^{\circ} \mathrm{C}$ and $5 \% \mathrm{CO}_{2}$. The resulting formazan crystals were dissolved in DMSO. The absorbance was determined at $540 \mathrm{~nm}$. The results were expressed as a percentage of surviving cells over control cells.

Statistical analysis. The data are expressed as the means \pm standard deviation (SD). The statistical significance was determined using analysis of variance (ANOVA) followed by a multiple comparison test with Dunnett's adjustment. A value of $p<0.05$ was considered to indicate a statistically significant difffence.

\section{Results}

Treatment with $P Q$ suppresses the infiltration of inflammatory cells in the BALF of mice with LPS-induced ALI. The mice with LPS-induced ALI exhibited a significant increase in the number of inflammatory cells, including neutrophils and macrophages in BALF compared with the normal control mice (Fig. 1). In particular, the number of neutrophils and macrophages in BALF was markedly increased in the mice with LPS-induced ALI. However, the PQ-treated mice exhibited a marked decrease in the number of neutrophils and macrophages in BALF compared with the mice with LPS-induced ALI in a concentrationdependent manner. Treatment with DEX was used as a positive control. The mice treated with DEX also exhibited a decrease in the number of neutrophils and macrophages in BALF compared with the LPS-exposed mice. The effects of DEX were similar to those of treatment with PQ at $15 \mathrm{mg} / \mathrm{kg}$.

Treatment with $P Q$ reduces the production of $R O S$ and proinflammatory cytokines in BALF. Given the fact that ALI is involved in neutrophil migration, the release of ROS and cytokine production (12), the levels of ROS and cytokines were examined in BALF. The levels of ROS were significantly increased in the LPS-exposed mice compared with the normal control mice (Fig. 2A). The mice treated with PQ at a dose of $15 \mathrm{mg} / \mathrm{kg}$ exhibited a significant reduction in ROS production compared with the LPS-exposed mice. Similar to the results obtained for ROS, the LPS-exposed mice exhibited a marked increase in the levels of TNF- $\alpha$ and IL-6, compared with the normal control mice, and the PQ-treated mice exhibited significantly decreased levels of TNF- $\alpha$ and IL- 6 compared with the LPS-exposed mice (Fig. 2B and C). To further examine the effects of PQ on the production of pro-inflammatory cytokines (27), the levels of IL-6 were detected using ELISA in serum of mice. As 

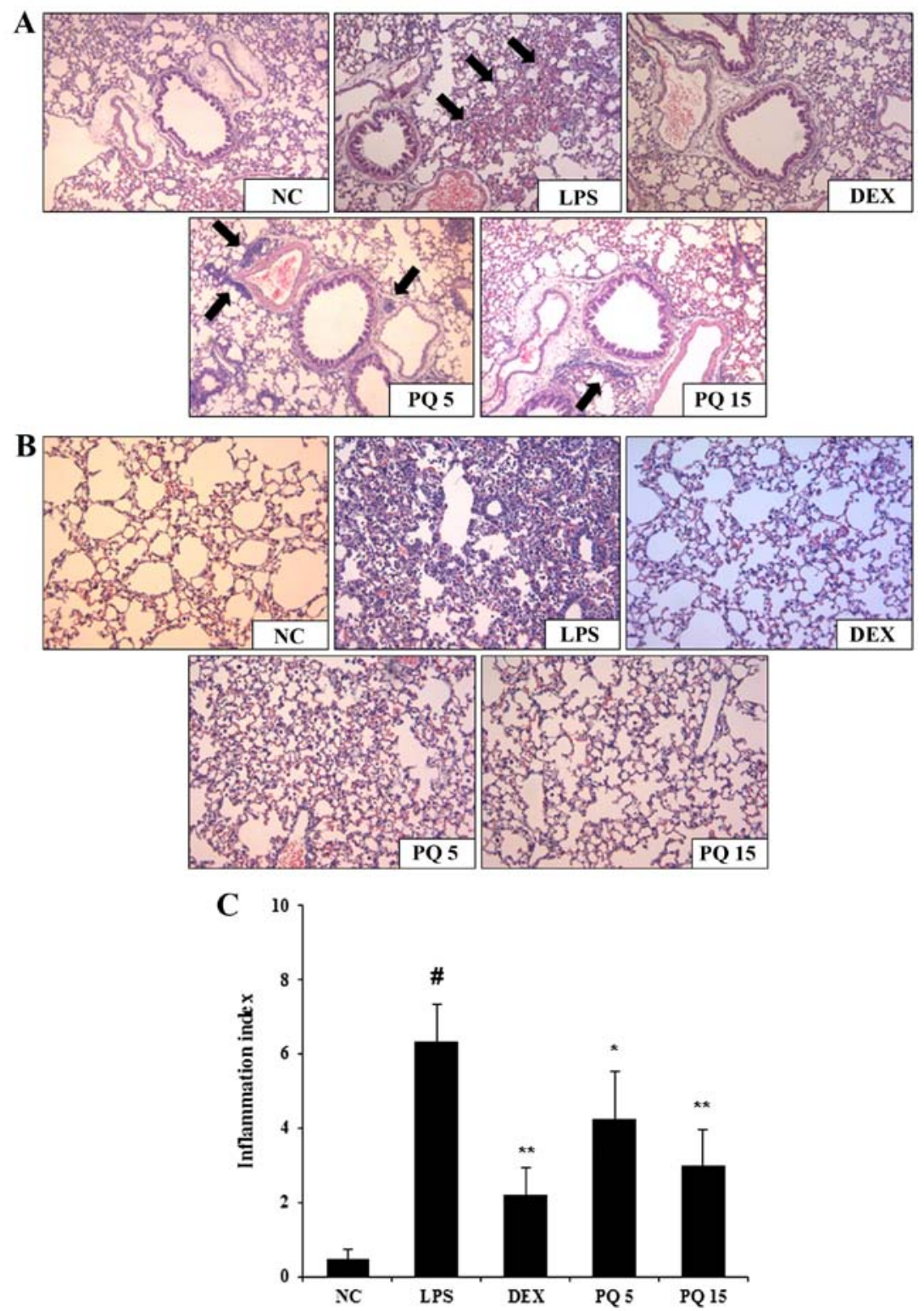

Figure 3. Picrasma quassiodes (D. Don) Benn. (PQ) attenuates airway inflammation induced by lipopolysaccharide (LPS). Histological examination of the airway inflammation of (A) peribronchial lesion (magnification x200) and (B) alveolar lesion (magnification x400) stained with H\&E solution. NC, normal control mice; LPS, mice administered LPS; DEX, mice administered dexamethasone $(3 \mathrm{mg} / \mathrm{kg})+\mathrm{LPS} ; \mathrm{PQ} 5$ and 15 , mice administered 5 or $15 \mathrm{mg} / \mathrm{kg}$ PQ + LPS. (C) Quantitative analysis of airway inflammation; ${ }^{*} \mathrm{p}<0.01$ indicates a statistically significant difference from the normal control group; ${ }^{*} \mathrm{p}<0.05$ and ${ }^{* *} \mathrm{p}<0.01$ indicate statistically significant differences compared to the LPS group.

shown Fig. 2D, PQ significantly suppressed the release of IL-6 compared with the LPS-exposed mice. The mice treated with DEX also exhibited a decrease in the levels of ROS, TNF- $\alpha$ and IL-6 compared with the LPS-exposed mice. The effects of DEX were similar to those of treatment with PQ at $15 \mathrm{mg} / \mathrm{kg}$.

Treatment with $P Q$ decreases inflammatory cell infiltration into the lungs. The infiltration of inflammatory immune cells into the lungs is one of the common characteristics of ALI. As shown by histological analysis, the LPS-exposed mice exhibited extensive infiltration of inflammatory cells into the lung tissue (Fig. 3A and B). However, the PQ-treated mice exhibited a marked reduction in inflammatory cell infiltration induced by the LPS challenge. The mice treated with DEX also exhibited a decrease in airway inflamamation compared with the LPS-exposed mice. Again, the effects of DEX were similar to those of treatment with PQ at $15 \mathrm{mg} / \mathrm{kg}$.

Treatment with $P Q$ inhibits the expression of iNOS and increases the expression of $\mathrm{HO}-1$ in the lungs. iNOS has been shown to be involved in the pathogenesis of ALI (28). HO-1 inhibits the LPS-induced production of iNOS and proinflammatory cytokines, such as TNF- $\alpha$ and IL-6 (17). In this study, to examine the effects of PQ on LPS-induced ALI in mice, the expression of iNOS and HO-1 was detected using western blot analysis. As shown in Fig. 4A, the expression of iNOS was significantly increased in the lungs of mice with LPS-induced ALI. However, treatment with PQ significantly decreased iNOS expression compared with the LPS-exposed mice. In addition, PQ significantly increased the expression of 



Figure 4. Picrasma quassiodes (D. Don) Benn. (PQ) suppresses the expression of inducible nitric oxide synthase (iNOS) and increases the expression of heme oxygenase-1 (HO-1) in the lungs of mice withy lipopolysaccharide (LPS)induced acute lung injury (ALI). The levels of (A) iNOS and (B) HO-1 in the lungs were measured by western blot analysis. Quantitative analysis was performed by densitometric analysis. $\beta$-actin was used as an internal control. NC, normal control mice; LPS, mice administered LPS; DEX, mice administered dexamethasone ( $3 \mathrm{mg} / \mathrm{kg})+\mathrm{LPS}$; PQ15, mice administered $15 \mathrm{mg} / \mathrm{kg}$ $\mathrm{PQ}+$ LPS. Data are expressed as the means $\pm \mathrm{SD} ;{ }^{\#} \mathrm{p}<0.01$ indicates a statistically significantly difference from the normal control group; ${ }^{* *} \mathrm{p}<0.01$ indicates a statistically significant difference compared to the LPS group; ${ }^{* * * *} \mathrm{p}<0.01$ indicates a statistically significant difference compared to the normal control group.

A

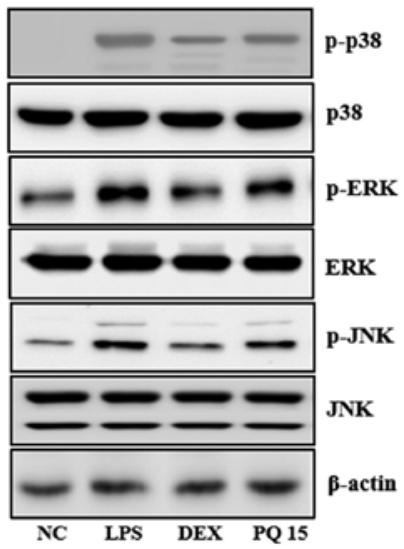

B $5.0, \square \mathrm{p}-\mathrm{p} 38 / \mathrm{p} 3 \mathrm{~S} \quad \square \mathrm{p}-\mathrm{ERK} / \mathrm{ERK} \quad \square \mathrm{p}-\mathrm{JNK} / \mathrm{NNK}$

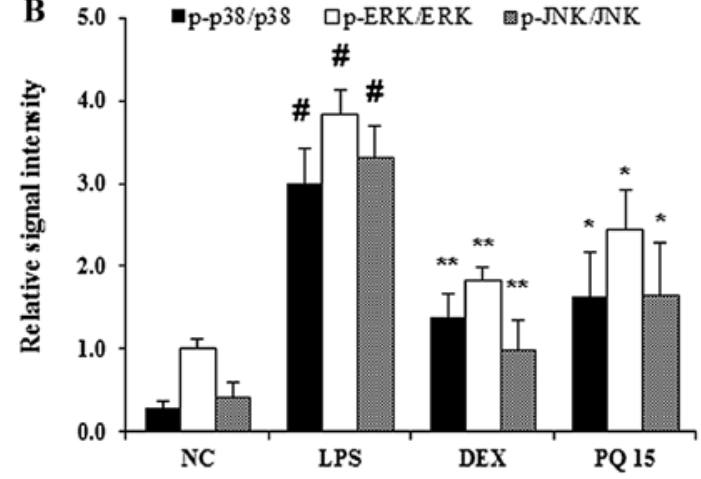

Figure 5. Picrasma quassiodes (D. Don) Benn. (PQ) decreases the activation of mitogen-activated protein kinases (MAPKs) in the lungs of mice with lipopolysaccharide (LPS)-induced acute lung injury (ALI). (A) The phosphorylation levels of p38, ERK and JNK were measured by western blot analysis. (B) Quantitative analysis of MAPK phosphorylation. NC, normal control mice; LPS, mice administered LPS; DEX, mice administered dexamethasone $(3 \mathrm{mg} / \mathrm{kg})+\mathrm{LPS} ; \mathrm{PQ} 15$, mice administered $15 \mathrm{mg} / \mathrm{kg} \mathrm{PQ}+\mathrm{LPS}$ Data are expressed as the means $\pm \mathrm{SD} ;{ }^{\#} \mathrm{p}<0.01$ indicates a statistically significant difference from the normal control group; ${ }^{*} \mathrm{p}<0.05$ and ${ }^{* *} \mathrm{p}<0.01$ indicate statistically significant differences compared to the LPS group.
Figure 6. Picrasma quassiodes (D. Don) Benn. (PQ) attenuates I $\kappa$ B degradation and nuclear factor- $\kappa \mathrm{B}(\mathrm{NF}-\kappa \mathrm{B})$ p65 phosphorylation in the lungs of mice with lipopolysaccharide (LPS)-induced acute lung injury (ALI). The levels of (A) IкB degradation and (B) NF- $\mathrm{B}$ p 65 phosphorylation were measured by western blot analysis. NC, normal control mice; LPS, mice administered LPS; DEX, mice administered dexamethasone $(3 \mathrm{mg} / \mathrm{kg})+\mathrm{LPS}$; PQ15, mice administered $15 \mathrm{mg} / \mathrm{kg}$ PQ + LPS. Data are expressed as the means $\pm \mathrm{SD} ;{ }^{\#} \mathrm{p}<0.01$ indicates a statistically significant difference from the normal control group. ${ }^{* *} \mathrm{p}<0.01$ indicates a statistically significant difference compared to the LPS group.

HO-1 in the lungs of mice with LPS-induced ALI (Fig. 4B). Treatment with DEX also decreased the expression of iNOS and increased the expression of HO-1 in the lungs of mice compared with the LPS-exposed mice. The effects of DEX were similar to those of treatment with PQ $(15 \mathrm{mg} / \mathrm{kg})$.

Treatment with $P Q$ suppresses MAPK activation in the lungs of mice with LPS-induced ALI. MAPKs are involved in the inflammatory response in ALI (2). It is also well known that LPS administration leads to the increased phosphorylation of p38, ERK and JNK in the lungs (17). In the present study, exposure to LPS significantly increased the phosphorylation of p38, ERK and JNK in the lungs of mice. However, treatment with PQ significantly decreased the LPS-induced MAPK phosphorylation compared with the mice with LPS-induced ALI (Fig. 5). Treatment with DEX also suppressed the activation of MAPKs in the lungs of mice compared with the LPS-exposed mice. Treatment with DEX was slightly more effective in reducing MAPK phosphorylation than treatment with PQ $(\mathrm{p}<0.01$ as opposed to $\mathrm{p}<0.05)$.

Treatment with $P Q$ decreases $I \kappa B$ degradation and $N F-\kappa B$ p65 phosphorylation in the lungs of mice with LPS-induced ALI.It is well known that the degradation of I $\mathrm{B}$ and the phosphorylation of NF- $\kappa \mathrm{B}$ p65 induces the transcription of most pro-inflammatory cytokines, including TNF- $\alpha$ and IL- 6 , thus playing a pivotal role in the pathogenesis of ALI (17). Thus, in the present study, to determine whether PQ affects the LPS-induced degradation of $\mathrm{I} \kappa \mathrm{B}$ and the phosphorylation of NF- $\kappa \mathrm{B}$ p 65 , the levels of $\mathrm{I} \kappa \mathrm{B}$ and the phosphorylation of NF- $\kappa \mathrm{B}$ were examined by western blot analysis. As shown in Fig. 6, the LPS administration induced the degradation of $\mathrm{I} \kappa \mathrm{B}$ and the phosphorylation of $\mathrm{NF}-\kappa \mathrm{B}$ p65. However, treatment with PQ significantly decreased the LPS-induced I $\kappa$ B degradation. In addition, PQ significantly 

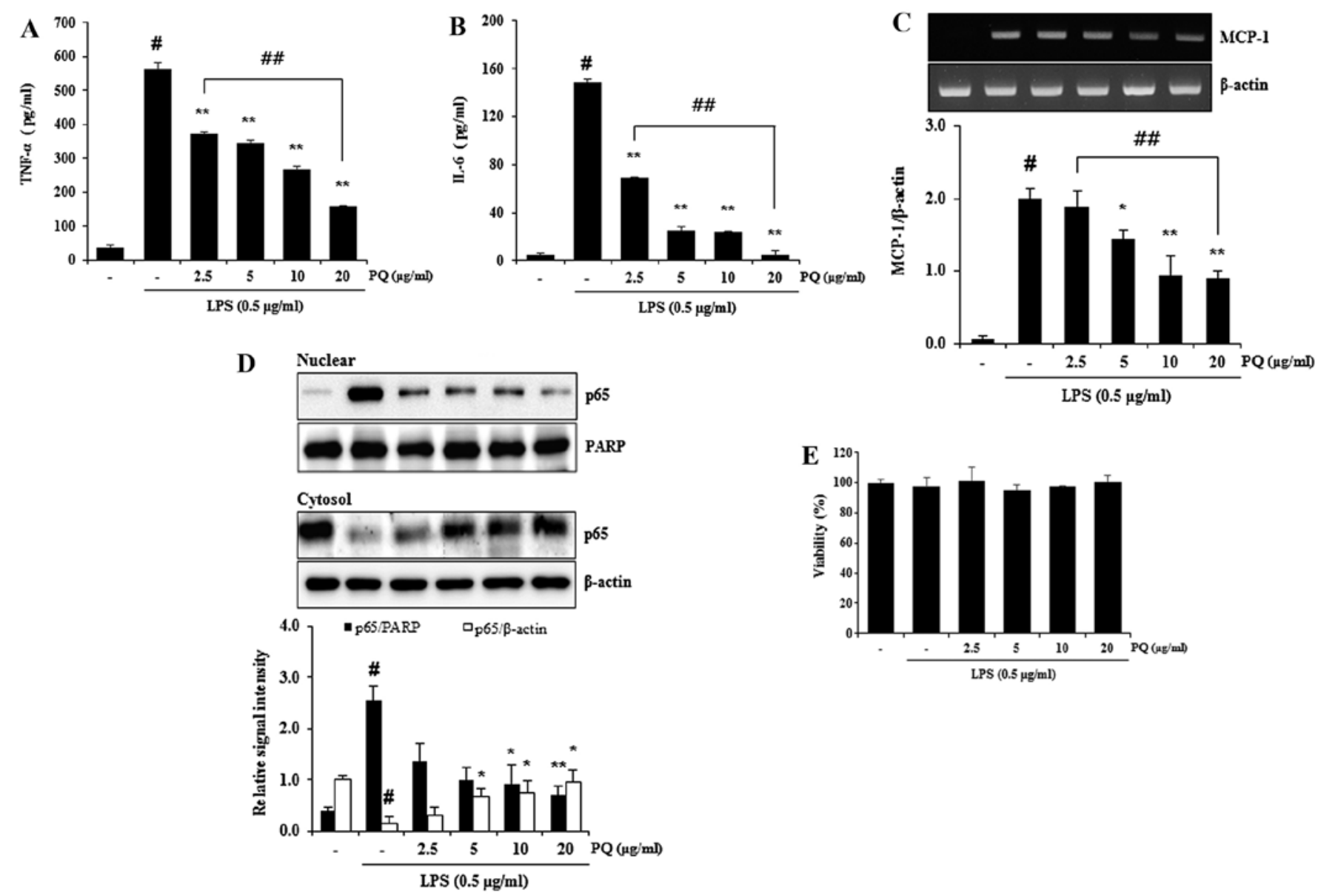

Figure 7. Picrasma quassiodes (D. Don) Benn. (PQ) reduces the release of tumor necrosis factor- $\alpha$ (TNF)- $\alpha$ and interleukin-6 (IL-6), and inhibits the increased mRNA expression of monocyte chemoattractant protein-1 (MCP-1) and the nuclear translocation of nuclear factor- $\kappa \mathrm{B}(\mathrm{NF}-\kappa \mathrm{B})$ in lipopolysaccharide (LPS)-stimulated RAW 264.7 macrophages. (A and B) The release of TNF- $\alpha$ and IL-6 was determined using cytokine ELISA kits. (C) The MCP-1 mRNA expression was determined by RT-PCR. (D) NF- $\kappa$ B nuclear translocation was measured by western blot analysis. PARP is a nuclear protein which was used as an internal control. (E) No noticeable cell death was observed by PQ and LPS. Data are expressed as the means \pm SD; ${ }^{\#}$ p $<0.01$ indicates a statistically significant difference from the control group (no treatment or stimulation); ${ }^{*} \mathrm{p}<0.05$ and ${ }^{* *} \mathrm{p}<0.01$ indicate statistically significant differences compared to the LPS-stimulated group; ${ }^{\# \#} \mathrm{p}<0.05$ indicates a statistically significant difference between the indicated groups.

decreased the phosphorylation of NF- $\mathrm{B}$ p 65 in the lungs of mice with LPS-induced ALI. Treatment with DEX also significantly suppressed the degradation of $\mathrm{I} \kappa \mathrm{B}$ and decreased the phosphorylation of NF- $\kappa \mathrm{B}$ p 65 in the lungs of mice compared to the LPS-exposed mice. The effects of DEX were similar to those of treatment with PQ $(15 \mathrm{mg} / \mathrm{kg})$.

Treatment with $P Q$ inhibits the release of TNF- $\alpha$ and $I L-6$, and decreases the $M R N A$ expression of MCP-1 and the nuclear translocation of NF- $\kappa B$ in LPS-stimulated RAW 264.7 macrophages. TNF- $\alpha$ and IL- 6 are major pro-inflammatory cytokines involved in the recruitment of neutrophils into the lungs of mice with LPS-induced ALI (17). MCP-1 is one of the key chemokines (29) that contributes to the recruitment of monocytes/macrophage into sites of immune response (30). NF- $\mathrm{B}$ is a major transcription factor that is a predominant regulator of numerous pro-inflammatory cytokines and mediators, such as TNF- $\alpha$, IL-6, iNOS and MCP-1 (31). We previously demonstrated that PQ attenuated the increase in iNOS protein expression in LPS-stimulated RAW 264.7 macrophages (26). In the present study, treatment with PQ inhibited the release of TNF- $\alpha$ and IL-6 from LPS-stimulated RAW 264.7 macrophages (Fig. 7A and B). Treatment with PQ also resulted in the suppression of $\mathrm{NF}-\kappa \mathrm{B}$ nuclear translocation, as well as in a decrease in MCP-1 expression in LPS-stimulated RAW 264.7 cells in a concentration-dependent manner (Fig. 7C and D). No noticeable cell death was observed following treatment with PQ at the concentration of up to $20 \mu \mathrm{g} / \mathrm{ml}$ (Fig. 7E).

Treatment with $P Q$ promotes the nuclear translocation of nuclear factor erythroid-2-related factor 2 (Nrf2) and the expression of $\mathrm{HO}-1$ in RAW 264.7 cells. Nrf2 is a pivotal transcription factor that regulates a variety of cytoprotective enzymes, including HO-1 (32). HO-1 is an antioxidant enzyme that can be induced by stimulants, such as inflammatory oxidants and cytokines, and the induction of HO-1 attenuates ALI (33). Therefore, in this study, we used western blot analysis to determine whether PQ promotes the nuclear translocation of Nrf2 in RAW 264.7 macrophages. As shown in Fig. 8A, treatment with PQ significantly increased the nuclear translocation of Nrf2 in the RAW 264.7 cells in a concentration-dependent manner. To examine whether PQ upregulates 

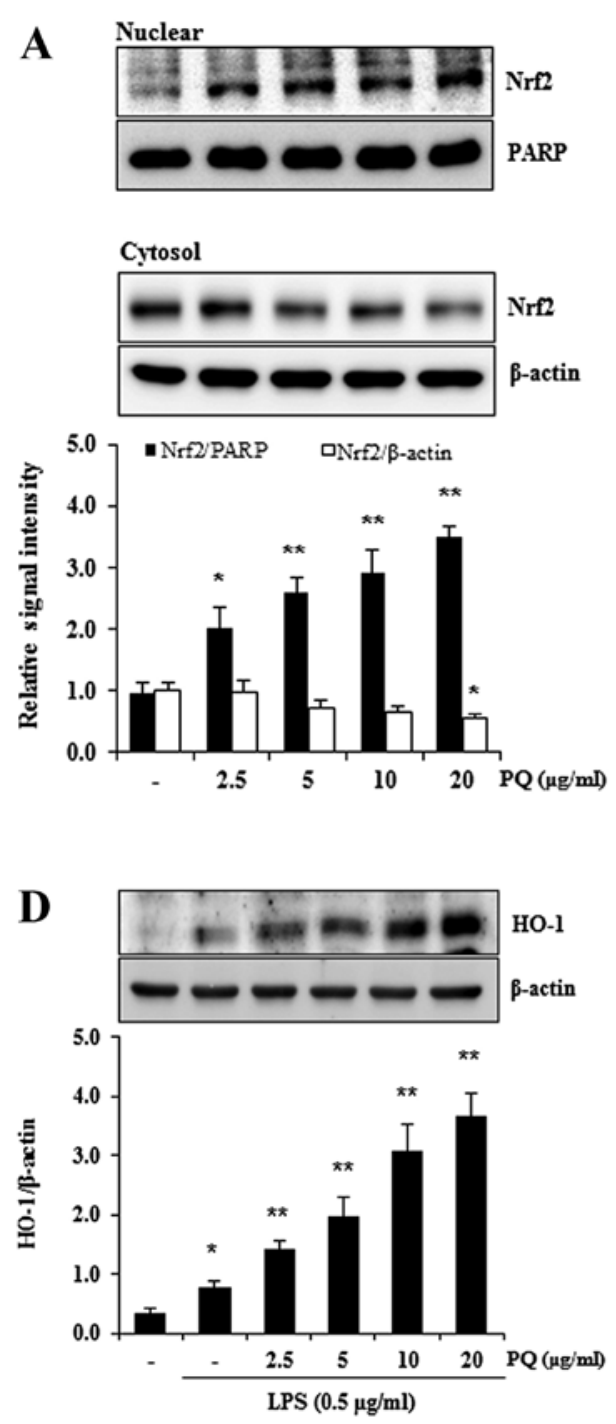


Figure 8. Picrasma quassiodes (D. Don) Benn. (PQ) promotes the nuclear translocation of nuclear factor erythroid-2-related factor 2 (Nrf2) and the expression of heme oxygenase-1 (HO-1) in RAW 264.7 cells. (A) The nuclear translocation of Nrf2 was determined by western blot analysis. Treatment with PQ promoted the Nrf2 nuclear translocation in a concentration-dependent manner. PARP is a nuclear protein which was used as an internal control. (B-E) HO-1 expression was determined by western blot anlysis and RT-PCR. PQ significantly increased the mRNA and protein levels of HO-1 in RAW 264.7 macrophgaes in a concentration-dependent manner. Data are expressed as the means $\pm \mathrm{SD} ;{ }^{*} \mathrm{p}<0.05$ and ${ }^{* *} \mathrm{p}<0.01$ indicate statistically significant differences compared to the control group (no treatment or stimulation).

HO-1 expression, the protein and mRNA levels of HO-1 were examined by western blot analysis and RT-PCR. Treatment with PQ resulted in a significant increase in the protein and mRNA expression of HO-1 in the RAW 264.7 macrophages in a concentration-dependent manner (Fig. 8B and C). In accordance with the increased expression of HO-1, PQ also significantly upregulated the protein and mRNA expression of HO-1 in the LPS-stimulated RAW 264.7 macrophages in a concentration-dependent manner (Fig. 8D and E).

Treatment with $P Q$ attenuates the activation of $p 38 M A P K$ in LPS-stimulated RAW 264.7 cells. To determine whether PQ affects the activation of MAPKs in LPS-stimulated
RAW 264.7 cells, the phosphorylation levels of MAPKs were measured by western blot analysis. Exposure to LPS markedly increased the phosphorylation of MAPKs in the RAW 264.7 cells. However, treatment with PQ significantly decreased the phosphorylation of p38 MAPK in the LPS-stimulated RAW 264.7 cells (Fig. 9).

\section{Discussion}

ALI is a major cause of acute respiratory failure (34) and remains a significant cause of morbidity and mortality in critically ill patients $(35,36)$. Infection is the most common cause of ALI (4). The intranasal administration of LPS in mice has been 
A
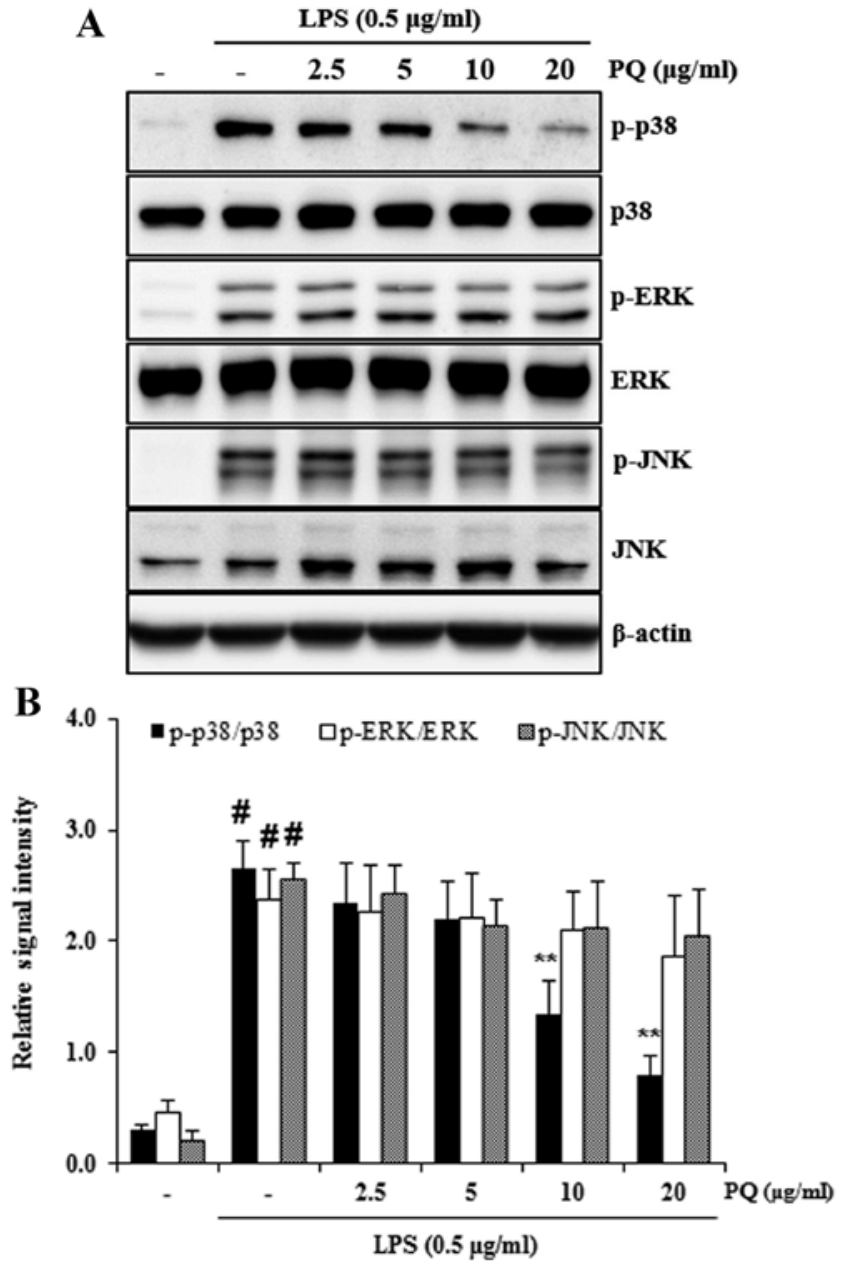

Figure 9. Picrasma quassiodes (D. Don) Benn. (PQ) attenuates the activation of p38 mitogen-activated protein kinase (MAPK) in lipopolysaccharide (LPS)-stimulated RAW 264.7 cells. (A) The protein expression of MAPK including p38, ERK and JNK was examined by western blot analysis. (B) Quantitative analysis of MAPK phosphorylation. Data are expressed as the means $\pm \mathrm{SD} ;{ }^{*} \mathrm{p}<0.01$ indicates a statistically significantly difference from the control group (no treatment or stimulation). ${ }^{*} \mathrm{p}<0.05$ and ${ }^{* *} \mathrm{p}<0.01$ indicate statistically significant differences compared to the LPS-stimulated group.

reported to induce neutrophil influx and lung damage (37), and has gained wide acceptance as a model of ALI and severe lung injury (38). The recruitment and activation of neutrophils (12) and macrophages (10) can lead to lung damage by promoting the generation of ROS (7) and pro-inflammatory mediators (39). In this study, the intranasal administration of LPS increased the infiltration of neutrophils and macrophages in the BALF and in the lungs of mice with ALI. The administration of LPS also increased the production of ROS in the BALF of mice with ALI. However, treatment with PQ attenuated the recruitment of neutrophils and macrophages, as well as the production of ROS (Figs. 1, 2A and 3A).

Pro-inflammatory cytokines have been reported to play an important role in the pathogenesis of ALI (40). Increased levels of TNF- $\alpha$ and IL- 6 can eventually increase iNOS expression in LPS-induced ALI $(3,41)$. Increased levels of NO produced by iNOS are believed to be involved in inflammatory disorders, including ALI(42). It has been reported that the inhibition of iNOS attenuates ALI (43). It is also well known that iNOS-knockout mice have less lung inflammation compared with wild-type mice $(44,45)$. In the present study, treatment with PQ reduced the production of pro-inflammatory cytokines, such as TNF- $\alpha$ and IL- 6 in the BALF of mice with LPS-induced ALI and iin LPS-stimulated RAW 264.7 macrophages (Figs. 2B-D, and 7A and B). PQ also decreased the expression of iNOS in the lungs of mice with LPS-induced ALI (Fig. 4A). Therefore, these results indicate that PQ protects against LPS-induce ALI by decreasing the production of pro-inflammatory cytokines and mediators, such as TNF- $\alpha$, IL- 6 and iNOS.

Nrf2 is an antioxidant transcription factor that is essential for protection against acute pulmonary injury (46). HO-1 is an inducible stress protein that is induced by Nrf2 and exerts anti-inflammatory effects in ALI (47). Previous studies have demonstrated that the induction of HO-1 inhibits the infiltration of neutrophils and macrophages (48), and the production of pro-inflammatory cytokines, including TNF- $\alpha$ in response to LPS $(17,20)$. It is also well known that the upregulation of HO-1 expression is involved in the inhibitory effects against LPS-induced iNOS expression (2). The present data demonstrated that HO-1 expression was significantly increased by treatment with PQ in the lungs of mice with LPS-induced ALI (Fig. 4B) and in RAW 264.7 macrophages (Fig. 8B-D). Treatment with PQ also promoted the Nrf2 nuclear translocation in RAW 264.7 macrophages in a concentration-dependent manner (Fig. 8A). These findings are in accordance with those of previous studies that demonstrated the protective role of HO-1 in ALI $(49,50)$.

The MAPK signaling pathways play a crucial role in the production of pro-inflammatory cytokines and mediators induced by LPS (13). MAPK phosphorylation is regarded as a critical step in the expression of iNOS in LPS-induced ALI in mice (51). MAPKs also play an important role in the regulation of pro-inflammatory cytokines, such as TNF- $\alpha$ and IL-6 in ALI induced by LPS in mice (52). Furthermore, the inhibition of MAPK activation is related to the suppression of MCP-1 expression in LPS-stimulated RAW 264.7 cells (53). In the present study, PQ suppressed the phosphorylation of MAPKs in the lungs of mice with LPS-induced ALI (Fig. 5A and B). PQ also reduced the activation of p38 MAPK in LPS-stimulated RAW 264.7 macrophages (Fig. 9A).

$\mathrm{NF}-\mathrm{\kappa B}$ is an important transcription factor responsible for the expression of a variety of pro-inflammatory mediators, including iNOS, TNF- $\alpha$, IL-6 and MCP-1 (54) and its downstream genes have been associated with various pathological conditions, including ALI (3). It is well known that LPS causes the nuclear transcription of the p65 subunit of NF- $\mathrm{kB}$ through I $\mathrm{B}$ degradation (17). The present data demonstrated that treatment with PQ significantly suppressed of $\mathrm{p} 65$ phosphorylation, as well as IKB degradation in the lungs of mice with LPS-induced ALI (Fig. 6A). Furthermore, treatment with PQ inhibited mRNA expression of MCP-1 and the nuclear translocation of NF- $\mathrm{KB}$ in LPS-stimulated RAW 264.7 macrophages in a concentration-dependent manner (Fig. 7C and D).

In conclusion, the data from the present study clearly demonstrated that PQ attenuated the infiltration of neutrophils and macrophages, and reduced the production of inflammatory mediators, such as ROS, TNF- $\alpha$, IL-6 and iNOS in an animal model of LPS-induced ALI. PQ also elevated the expression of HO-1, and suppressed the activation of NF- $\mathrm{KB}$ and MAPKs in the lungs of mice with ALI. In LPS-stimulated 
RAW 264.7 macrophages, PQ suppressed the release of TNF- $\alpha$ and IL-6, and the expression of MCP-1. PQ also inhibited the nuclear translocation of $\mathrm{NF}-\kappa \mathrm{B}$, and promoted the nuclear translocation of Nrf2 and increased the expression of HO-1 in RAW 264.7 cells. Furthermore, PQ inhibited the activation of p38 MAPK in LPS-stimulated RAW 264.7 cells. These results suggest that PQ may be a valuable therapeutic agent for use in the treatment of ALI.

\section{Acknowledgements}

This study was supported by the KRIBB Research Initiative Program (KGM 1221521) of the Republic of Korea.

\section{References}

1. Rubenfeld GD, Caldwell E, Peabody E, Weaver J, Martin DP, Neff M, Stern EJ and Hudson LD: Incidence and outcomes of acute lung injury. N Engl J Med 353: 1685-1693, 2005.

2. Zhang Y, Liang D, Dong L, Ge X, Xu F, Chen W, Dai Y, Li H, Zou P, Yang S and Liang G: Anti-inflammatory effects of novel curcumin analogs in experimental acute lung injury. Respir Res 16: 43, 2015.

3. Shin NR, Shin IS, Song HH, Hong JM, Kwon OK, Jeon CM, Kim JH, Lee SW, Lee JK, Jin H, et al: Callicarpa japonica Thunb. reduces inflammatory responses: a mouse model of lipopolysaccharide-induced acute lung injury. Int Immunopharmacol 26: 174-180, 2015.

4. Sun XJ, Li XQ, Wang XL, Tan WF and Wang JK: Sevoflurane inhibits nuclear factor- $\kappa \mathrm{B}$ activation in lipopolysaccharide-induced acute inflammatory lung injury via toll-like receptor 4 signaling. PLoS One 10: e0122752, 2015.

5. Huang X, Tang J, Cai H, Pan Y, He Y, Dai C, Chen A, Yu X, Chen M, Zou L and Wang L: Anti-inflammatory effects of monoammonium glycyrrhizinate on lipopolysaccharide-induced acute lung injury in mice through regulating nuclear factor-kappa B signaling pathway. Evid Based Complement Alternat Med 2015: $272474,2015$.

6. Auten RL, Whorton MH and Nicholas Mason S: Blocking neutrophil influx reduces DNA damage in hyperoxia-exposed newborn rat lung. Am J Respir Cell Mol Biol 26: 391-397, 2002.

7. Grommes J, Vijayan S, Drechsler M, Hartwig H, Mörgelin M, Dembinski R, Jacobs M, Koeppel TA, Binnebösel M, Weber C and Soehnlein O: Simvastatin reduces endotoxin-induced acute lung injury by decreasing neutrophil recruitment and radical formation. PLoS One 7: e38917, 2012.

8. Farley KS, Wang LF, Law C and Mehta S: Alveolar macrophage inducible nitric oxide synthase-dependent pulmonary microvascular endothelial cell septic barrier dysfunction. Microvasc Res 76: 208-216, 2008.

9. Wang L, Taneja R, Razavi HM, Law C, Gillis C and Mehta S: Specific role of neutrophil inducible nitric oxide synthase in murine sepsis-induced lung injury in vivo. Shock 37: 539-547, 2012.

10. Beck-Schimmer B, Schwendener R, Pasch T, Reyes L, Booy C and Schimmer RC: Alveolar macrophages regulate neutrophil recruitment in endotoxin-induced lung injury. Respir Res 6: 61, 2005.

11. Takashima K, Matsushima M, Hashimoto K, Nose H, Sato M, Hashimoto N, Hasegawa Y and Kawabe T: Protective effects of intratracheally administered quercetin on lipopolysaccharide-induced acute lung injury. Respir Res 15: 150, 2014.

12. Grommes J and Soehnlein O: Contribution of neutrophils to acute lung injury. Mol Med 17: 293-307, 2011.

13. Yang H, Li Y, Huo P, Li XO, Kong D, Mu W, Fang W, Li L, Liu N, Fang L, et al: Protective effect of Jolkinolide B on LPS-induced mouse acute lung injury. Int Immunopharmacol 26: 119-124, 2015.

14. Akbarshahi H, Rosendahl AH, Westergren-Thorsson G and Andersson R: Acute lung injury in acute pancreatitis - awaiting the big leap. Respir Med 106: 1199-1210, 2012.

15. Chi G, Wei M, Xie X, Soromou LW, Liu F and Zhao S: Suppression of MAPK and NF- $\kappa$ B pathways by limonene contributes to attenuation of lipopolysaccharide-induced inflammatory responses in acute lung injury. Inflammation 36: 501-511, 2013.
16. Huang GJ, Deng JS, Chen CC, Huang CJ, Sung PJ, Huang SS and Kuo YH: Methanol extract of Antrodia camphorata protects against lipopolysaccharide-induced acute lung injury by suppressing NF- $\mathrm{BB}$ and MAPK pathways in mice. J Agric Food Chem 62: 5321-5329, 2014.

17. Yeh CH, Yang JJ, Yang ML, Li YC and Kuan YH: Rutin decreases lipopolysaccharide-induced acute lung injury via inhibition of oxidative stress and the MAPK-NF- $\kappa \mathrm{B}$ pathway. Free Radic Biol Med 69: 249-257, 2014.

18. Lee JW, Kwon JH, Lim MS, Lee HJ, Kim SS, Lim SY and Chun W: 3,4,5-Trihydroxycinnamic acid increases heme-oxygenase-1 (HO-1) and decreases macrophage infiltration in LPS-induced septic kidney. Mol Cell Biochem 397: 109-116, 2014.

19. Lee JW, Bae CJ, Choi YJ, Kim SI, Kwon YS, Lee HJ, Kim SS and Chun W: 3,4,5-Trihydroxycinnamic acid inhibits lipopolysaccharide (LPS)-induced inflammation by Nrf2 activation in vitro and improves survival of mice in LPS-induced endotoxemia model in vivo. Mol Cell Biochem 390: 143-153, 2014

20. Yin H, Li X, Gong Q, Jin X, Gu H, Yuan B, Zhang B, Zheng F, Gong $\mathrm{F}$ and $\mathrm{Zhu} \mathrm{J}$ : Heme oxygenase-1 upregulation improves lipopolysaccharide-induced acute lung injury involving suppression of macrophage migration inhibitory factor. Mol Immunol 47: 2443-2449, 2010.

21. Hashiba T, Suzuki M, Nagashima Y, Suzuki S, Inoue S, Tsuburai T, Matsuse $T$ and Ishigatubo $Y$ : Adenovirus-mediated transfer of heme oxygenase-1 cDNA attenuates severe lung injury induced by the influenza virus in mice. Gene Ther 8: 1499-1507, 2001.

22. Zhao W, Yu J, Su Q, Liang J, Zhao L, Zhang Y and Sun W: Antihypertensive effects of extract from Picrasma quassiodes (D. Don) Benn. in spontaneously hypertensive rats. J Ethnopharmacol 145: 187-192, 2013.

23. Zhao W, Sun C, He J, Chen L, Zhang Y and Sun W: The possible mechanisms of Picrasma quassiodes (D. Don) Benn. in the treatment of colitis induced by 2,4,6-trinitrobenzene sulfonic acid in mice. J Ethnopharmacol 145: 424-430, 2013.

24. Zhang Q, Shu X, Jing F, Wang X, Lin C and Luo A: Preparative separation of alkaloids from Picrasma quassioides (D. Don) Benn. by conventional and $\mathrm{pH}$-zone-refining countercurrent chromatography. Molecules 19: 8752-8761, 2014.

25. Fan H, Qi D, Yang M, Fang H, Liu K and Zhao F: In vitro and in vivo anti-inflammatory effects of 4-methoxy-5- hydroxycanthin-6-one, a natural alkaloid from Picrasma quassioides. Phytomedicine 20: 319-323, 2013.

26. Shin NR, Shin IS, Jeon CM, Hong JM, Oh SR, Hahn KW and Ahn KS: Inhibitory effects of Picrasma quassioides (D.Don) Benn. on airway inflammation in a murine model of allergic asthma. Mol Med Rep 10: 1495-1500, 2014.

27. Liu YL, Liu YJ, Liu Y, Li XS, Liu SH, Pan YG, Zhang J, Liu Q and Hao YY: Hydroxysafflor yellow A ameliorates lipopolysaccharide-induced acute lung injury in mice via modulating toll-like receptor 4 signaling pathways. Int Immunopharmacol 23: 649-657, 2014.

28. Farley KS, Wang LF, Razavi HM, Law C, Rohan M, McCormack DG and Mehta S: Effects of macrophage inducible nitric oxide synthase in murine septic lung injury. Am J Physiol Lung Cell Mol Physiol 290: L1164-L1172, 2006.

29. Deshmane SL, Kremlev S, Amini S and Sawaya BE: Monocyte chemoattractant protein-1 (MCP-1): an overview. J Interferon Cytokine Res 29: 313-326, 2009.

30. Takahashi M, Galligan C, Tessarollo L and Yoshimura T: Monocyte chemoattractant protein-1 (MCP-1), not MCP-3, is the primary chemokine required for monocyte recruitment in mouse peritonitis induced with thioglycollate or zymosan A. J Immunol 183: 3463-3471, 2009.

31. Cheung DW, Koon CM, Wat E, Ko CH, Chan JY, Yew DT, Leung PC, Chan WY, Lau CB and Fung KP: A herbal formula containing roots of Salvia miltiorrhiza (Danshen) and Pueraria lobata (Gegen) inhibits inflammatory mediators in LPS-stimulated RAW 264.7 macrophages through inhibition of nuclear factor $\kappa \mathrm{B}(\mathrm{NF} \kappa \mathrm{B})$ pathway. J Ethnopharmacol 145: 776-783, 2013.

32. Kim KH, Kwun MJ, Han CW, Ha KT, Choi JY and Joo M: Suppression of lung inflammation in an LPS-induced acute lung injury model by the fruit hull of Gleditsia sinensis. BMC Complement Altern Med 14: 402, 2014.

33. Wang F, Meng Y, Zhang Y, Zhao G, Zheng X, Xiao Q and Yu Y: Ketamine reduces lipopolysaccharide-induced high-mobility group box-1 through heme oxygenase-1 and nuclear factor erythroid 2-related factor $2 / \mathrm{p} 38$ mitogen-activated protein kinase. J Surg Res 194: 599-613, 2015. 
34. Liu KD and Matthay MA: Advances in critical care for the nephrologist: acute lung injury/ARDS. Clin J Am Soc Nephrol 3: 578-586, 2008.

35. Jin S, Merchant ML, Ritzenthaler JD, McLeish KR, Lederer ED, Torres-Gonzalez E, Fraig M, Barati MT, Lentsch AB, Roman J, et al: Baclofen, a GABABR agonist, ameliorates immune-complex mediated acute lung injury by modulating pro-inflammatory mediators. PLoS One 10: e0121637, 2015.

36. Johnson ER and Matthay MA: Acute lung injury: epidemiology, pathogenesis, and treatment. J Aerosol Med Pulm Drug Deliv 23: 243-252, 2010

37. Corteling R, Wyss D and Trifilieff A: In vivo models of lung neutrophil activation. Comparison of mice and hamsters. BMC Pharmacol 2: 1, 2002.

38. Liu XX, Yu DD, Chen MJ, Sun T, Li G, Huang WJ, Nie H, Wang C, Zhang YX, Gong Q and Ren BX: Hesperidin ameliorates lipopolysaccharide-induced acute lung injury in mice by inhibiting HMGB1 release. Int Immunopharmacol 25: 370-376, 2015.

39. Guo L, Li S, Zhao Y, Qian P, Ji F, Qian L, Wu X and Qian G: Silencing angiopoietin-like protein 4 (ANGPTL4) protects against lipopolysaccharide-induced acute lung injury via regulating SIRT1 /NF-kB pathway. J Cell Physiol 230: 2390-2402, 2015.

40. Fu K, Piao T, Wang M, Zhang J, Jiang J, Wang X and Liu H: Protective effect of catalpol on lipopolysaccharide-induced acute lung injury in mice. Int Immunopharmacol 23: 400-406, 2014.

41. Zhang SY, Xu LT, Li AX and Wang SM: Effects of ergosterol, isolated from Scleroderma Polyrhizum Pers., on lipopolysaccharide-induced inflammatory responses in acute lung injury. Inflammation 38: 1979-1985, 2015.

42. Chen T, Mou Y, Tan J, Wei L, Qiao Y, Wei T, Xiang P, Peng S, Zhang Y, Huang Z and Ji $\mathrm{H}$ : The protective effect of CDDO-Me on lipopolysaccharide-induced acute lung injury in mice. Int Immunopharmacol 25: 55-64, 2015.

43. Zhang WZ, Jiang ZK, He BX and Liu XB: Arctigenin protects against lipopolysaccharide-induced pulmonary oxidative stress and inflammation in a mouse model via suppression of MAPK, HO-1, and iNOS signaling. Inflammation 38: 1406-1414, 2015.

44. Harkin DW, Rubin BB, Romaschin A and Lindsay TF: Selective inducible nitric oxide synthase (iNOS) inhibition attenuates remote acute lung injury in a model of ruptured abdominal aortic aneurysm. J Surg Res 120: 230-241, 2004.
45. Speyer CL, Neff TA, Warner RL, Guo RF, Sarma JV, Riedemann NC, Murphy ME, Murphy HS and Ward PA: Regulatory effects of iNOS on acute lung inflammatory responses in mice. Am J Pathol 163: 2319-2328, 2003.

46. Jiang T, Huang Z, Chan JY and Zhang DD: Nrf2 protects against As(III)-induced damage in mouse liver and bladder. Toxicol Appl Pharmacol 240: 8-14, 2009.

47. Shin IS, Hong J, Jeon CM, Shin NR, Kwon OK, Kim HS, Kim JC, Oh SR and Ahn KS: Diallyl-disulfide, an organosulfur compound of garlic, attenuates airway inflammation via activation of the Nrf-2/HO-1 pathway and NF-kappaB suppression. Food Chem Toxicol 62: 506-513,2013.

48. Hualin C, Wenli X, Dapeng L, Xijing L, Xiuhua P and Qingfeng P: The anti-inflammatory mechanism of heme oxygenase- 1 induced by hemin in primary rat alveolar macrophages. Inflammation 35 : 1087-1093, 2012.

49. Han CW, Kwun MJ, Kim KH, Choi JY, Oh SR, Ahn KS, Lee JH and Joo M: Ethanol extract of Alismatis Rhizoma reduces acute lung inflammation by suppressing NF- $\mathrm{KB}$ and activating Nrf2. J Ethnopharmacol 146: 402-410, 2013.

50. Kung CW, Lee YM, Cheng PY, Peng YJ and Yen MH: Ethyl pyruvate reduces acute lung injury via regulation of iNOS and HO-1 expression in endotoxemic rats. J Surg Res 167: e323-e331, 2011.

51. Li KC, Ho YL, Hsieh WT, Huang SS, Chang YS and Huang GJ: Apigenin-7-glycoside prevents LPS-induced acute lung injury via downregulation of oxidative enzyme expression and protein activation through inhibition of MAPK phosphorylation. Int J Mol Sci 16: 1736-1754, 2015

52. San Z, Fu Y, Li W, Zhou E, Li Y, Song X, Wang T, Tian Y, Wei Z, Yao M, et al: Protective effect of taraxasterol on acute lung injury induced by lipopolysaccharide in mice. Int Immunopharmacol 19: $342-350,2014$.

53. Sogo T, Terahara N, Hisanaga A, Kumamoto T, Yamashiro T, Wu S, Sakao K and Hou DX: Anti-inflammatory activity and molecular mechanism of delphinidin 3-sambubioside, a Hibiscus anthocyanin. Biofactors 41: 58-65, 2015.

54. Jing W, Chunhua M and Shumin W: Effects of acteoside on lipopolysaccharide-induced inflammation in acute lung injury via regulation of NF- $\mathrm{kB}$ pathway in vivo and in vitro. Toxicol Appl Pharmacol 285: 128-135, 2015. 